\title{
Sensory Profile of Fermented Arabica Coffee in the Perception of American Cupping Tasters
}

\author{
Lucas Louzada Pereira ${ }^{*}$, Rogério Carvalho Guarçoni², Tais Rizzo Moreira ${ }^{3}$, \\ Dério Brioschi Jr. ${ }^{1}$, João Paulo Pereira Marcate1, Luiz Henrique Bozzi Pimenta de Sousa1, \\ Aldemar Polonini Moreli', Danieli Grancieri Debona1, Carla Schwengber Ten Caten ${ }^{4}$
}

\footnotetext{
${ }^{1}$ Federal Institute of Education Science and Technology of Espírito Santo, Venda Nova do Imigrante Campus, Food Science and Technology Program, Rua Elizabeth Minete Perim, Vitória, Brazil

${ }^{2}$ Capixaba Institute for Technical Assistance, Research and Extension, INCAPER, Department of Statistics, Domingos Martins, Brazil

${ }^{3}$ Department of Forest Sciences and Wood, Federal University of Espírito Santo, Center for Agrarian Sciences and Engineering, Jerônimo Monteiro, Brazil

${ }^{4}$ Department of Production and Transportation Engineering, Federal University of Rio Grande do Sul, Porto Alegre, Brazil

Email: *luca slozada@hotmail.com
}

How to cite this paper: Pereira, L.L., Guarçoni, R.C., Moreira, T.R., Brioschi Jr., D., Marcate, J.P.P., de Sousa, L.H.B.P., Moreli, A.P., Debona, D.G. and Caten, C.S.T. (2019) Sensory Profile of Fermented Arabica Coffee in the Perception of American Cupping Tasters. Agricultural Sciences, 10, 321-329. https://doi.org/10.4236/as.2019.103027

Received: January 31, 2019

Accepted: March 10, 2019

Published: March 13, 2019

Copyright $\odot 2019$ by author(s) and Scientific Research Publishing Inc. This work is licensed under the Creative Commons Attribution-NonCommercial International License (CC BY-NC 4.0). http://creativecommons.org/licenses/by-nc/4.0/ (c) (i) (8) Open Access

\begin{abstract}
The consumption of specialty coffees has been growing year after year, indicating that several niches and market forms according to the sensorial orientation of the consumers, as well as the cupping tasters and agents are responsible for the composition of blends, and for the physical and sensory classification of the coffees in the industry. This study presented 5 methods of spontaneous and induced fermentation to different North American cupping tasters, in order to evaluate coffee quality potential, based on the Specialty Coffee Association (SCA) protocol. During the months of May to July of 2017, 150 coffee samples were evaluated. Initial results indicate that North American cupping tasters evaluated dry fermented coffees using yeast culture as superiors, in the sensorial aspect, than the more conventional methods in Brazil. Such indication opens new discussions on the acceptance of a determined product, followed by the potential for modification of the sensory route as of the fermentation that will affect the attributes.
\end{abstract}

\section{Keywords}

Arabica Coffee, Fermentation, Acceptance, Cupping Tasters

\section{Introduction}

Data from the US Department of Agriculture show that the world consumes ap- 
proximately 9 million tons of coffee per year. Coffee is an important product for the Brazilian and World economies. Brazil is the largest producer and exporter of coffee in the world and has two economically important species: arabica coffee and canephora coffee (conilon), with arabica coffee accounting for $81 \%$ and conilon for $19 \%$ of the area under cultivation in the country [1].

In order for the coffee to reach the final consumers' table, a series of processes take place, from harvesting, processing, drying and storage, to industrialization. However, the crucial point in the last decades has been in the wet processing, with the introduction of induced fermentation [2] and those with spontaneous fermentation studies [3].

When done correctly, wet processing with induced fermentation ensures that the intrinsic qualities of the coffee beans are preserved for a long time, producing a homogeneous coffee with few defective grains. Thus, coffee produced by this method is generally considered to be of better quality and commands the highest prices in the global market [4].

These processes are commonly complex; each coffee grower has its variations in post-harvest methodologies. Often, no agreement and exact standardization were observed for wet processing [5]. The shortcomings in controlling coffee processes on site, particularly in wet processing (fermentation), lead to defects and lack of consistency in product quality, causing losses to producers [6].

However, there is a great advance in the technology used in coffee plantations and new methods have been used to improve the quality of the grain, mainly in postharvest [7]. After this stage, coffee needs to be evaluated, so that quality is determined. At this time, the procedure of cup tasting, through tasters, using personal opinion and tasting experience accumulated over the years [8] [9]. The tasters are judges who perform the sensory analysis and are in charge of evaluating the coffee quality, consequently influencing the evaluation according to their perceptions. Often, it is up to these professionals to determine the final quality, thus interfering with the price of the product [10].

Based on the brief outline described above, the question is: What is the potential for acceptance of fermented Arabica coffee in the perception of North American tasters?

This study sought to understand and describe the potential for acceptance of spontaneous and induced fermented Arabica coffee from the perspective of graders from the United States of America. The study was conducted in Austin, Texas, in 2017, with a 6-judge panel that evaluated different methods employed in wet processing.

\section{Material and Methods}

\subsection{Sample Preparation: Wet Processing}

The producers, respecting the experimental design in previously demarcated areas, harvested coffee beans of the Catuaí Vermelho variety, from June to September of 2016. The raw materials used in the formulation of the worts were 
coffee pulp, coffee husk from peeling, water and yeast (Saccharomyces cerevisiae). Fifteen kilograms of coffee were harvested per experimental plot in both experiments, presenting $85 \%$ of ripe fruits. After harvest, the fruits were processed according to established procedures.

The raw materials used in the formulation of the musts were composed of: coffee pulp, bark from peeling, water and yeast (Saccharomyces cerevisiae). Twenty kilograms of coffee were harvested per experimental plot in all experiments, and after harvest the fruits were processed according to established procedures. 6 points were selected to develop this study in different places in Espírito Santo Coffee Single Origin.

The five processes had the following methodologies:

Process 1: fermentation must with water (W-Washed), $15 \mathrm{~kg}$ of peeled cherry coffee (pulp), $10 \mathrm{~kg}$ of bark and 10 liters of water.

Process 2: fermentation must with yeast starter culture (Saccharomyces cerevisiae-YF-Yeast fermentation) in a $1 \%$ (part of volume) of must, $15 \mathrm{~kg}$ of coffee pulped (pulp) $10 \mathrm{~kg}$ of bark, 10 liters of water.

Process 3: dry fermentation must (FWWY-Fully washed without yeast), 15 $\mathrm{kg}$ of peeled cherry coffee (pulp) and $10 \mathrm{~kg}$ of peel, without additional process water.

Process 4: dry fermentation must with yeast (FWY-Fully washed with yeast), fermentation must with yeast starter culture (Saccharomyces cerevisiae), in the proportion of $1 \%(\mathrm{p} / \mathrm{v})$ of the must, $15 \mathrm{~kg}$ of peeled cherry coffee (pulp), $5 \mathrm{~kg}$ of bark, without added water.

Process 5: semi-dry (SD-Semi-dry) process, fermentation with $15 \mathrm{~kg}$ peeled cherry coffee (pulp), without water. Drying in African Bed System (spontaneous fermentation).

In the four proposed methods, a wort was prepared with yeast culture ( $\mathrm{Sac}$ charomyces cerevisiae) and coffee husk. For the experiments, worts 1 and 2 received addition of water to the processing at the temperature of $38^{\circ} \mathrm{C}$ [11], and remained immersed in fermentation tanks in the processing laboratory of the Federal Institute of Espírito Santo (IFES) for 36 hours. Wort 3 received only coffee husk, from the wet processing, remaining in fermentation for 36 hours. Wort 4 only received husk and yeast (Saccharomyces cerevisiae) without addition of water. After the fermentation period, worts 1, 2, 3 and 4 were washed and taken to dry in a suspended and covered yard [5].

\subsection{Sensory Analysis}

The experiments were conducted in the Laboratory of Sensory Analysis of Casa Brasil Specialty Coffee with North American judges from May to July of 2017.

Roasting was conducted using the Laboratto TGP-2 roaster with the Agtron-SCAA disk set. The roasting point of these samples was set based on grain color between the colors determined by disks \#65 and \#55 for specialty coffees [12]. 
Roasting was executed within 24 hours of cupping and it was allowed to rest for 8 hours before grinding. All samples were roasted from 9 to 10 minutes. After roasting and cooling, the samples remained stored in sealed containers, according to the methodology of sensory analysis established by the SCAA.

The coffee samples were ground with Mahlkoenig EK-40 electric grinder, in the medium to coarse particle size range. Five cups of each batch of coffee were prepared for cupping. The optimal ratio of $8.25 \mathrm{~g}$ of coffee per $150 \mathrm{ml}$ of water was adopted, as this conforms to the mid-point of the balance chart, optimal to achieve the Golden Cup [12]. The infusion was performed after the water reached $92^{\circ} \mathrm{C}-95^{\circ} \mathrm{C}$. The Q-Graders began the evaluation when the temperature of the cups reached $55^{\circ} \mathrm{C}$, respecting the time of 4 minutes from the infusion to the evaluation.

\section{Sample Evaluation Method}

A centesimal numerical scale expresses the quality of a given batch of coffee, when evaluated through the SCAA method. It is expected that coffees that get high scores should, evidently, be better than coffees that receive lower scores, thus demonstrating the consistency of the method of descriptive sensory analysis.

The tasting form provides the possibility of evaluating eleven (11) important attributes for coffee: Fragrance/Aroma, Uniformity, Absence of Defects (Clean Cup), Sweetness, Flavor, Acidity, Body, Aftertaste, Balance, Defects and Overall evaluation. Highly positive results arise from the perception of a balanced group formed by the evaluated attributes.

A panel of six (6) cupping tasters carried out the sensory analysis of the coffees, aiming at reducing the subjectivity in the evaluation process [11] [13].

\subsection{Experimental Design}

The experiments were conducted in a randomized block design with five replicates, where five treatments were evaluated. For the statistical analyzes, joint analyzes of the experiments were carried out, in which the means were compared by the Tukey test, the regression models tested using the F test and the estimators by $t$ test. The sensory data were analyzed by the Complete Linkage Hierarchical Clustering method. The goal is to maximize the homogeneity of objects within groups, while maximizing the heterogeneity between the groups [14]. Statistical analyzes were performed using the software IBM SPSS Statistics Base 22.0.

\section{Results and Discussion}

The sensorial results expressed in Table 1 indicate the perception of North American cupping tasters ${ }^{1}$. During the sensorial tests, it was possible to observe the

\footnotetext{
${ }^{1}$ Cupping taster: In the coffee production chain, it is common for the evaluators, or tasters, to carry out the sensory analysis of the samples that are commercialized, from the sale of the raw material, to the final consumer. The cupping taster practice describes the method of sensory analysis that is used in evaluating coffee quality, which is usually employed by tasters or Q-graders with extensive experience.
} 
Table 1. Global score means evaluated in five treatments and at six altitudes.

\begin{tabular}{|c|c|c|c|c|c|c|c|c|c|c|c|c|c|c|}
\hline \multirow{3}{*}{$\begin{array}{c}\text { Treatment } \\
1\end{array}$} & \multicolumn{12}{|c|}{ Altitude (m) } & \multirow{2}{*}{\multicolumn{2}{|c|}{ Mean }} \\
\hline & \multicolumn{2}{|c|}{907.08} & \multicolumn{2}{|c|}{969} & \multicolumn{2}{|c|}{1005} & \multicolumn{2}{|c|}{1021} & \multicolumn{2}{|c|}{1052} & \multicolumn{2}{|c|}{1078.08} & & \\
\hline & 80.66 & A & 78.91 & $\mathrm{C}$ & 82.28 & A & 79.78 & B & 80.41 & B & 81.69 & B & 80.62 & $\mathrm{C}$ \\
\hline 2 & 81.11 & $\mathrm{~A}$ & 80.82 & B & 81.68 & $\mathrm{~A}$ & 80.53 & B & 81.56 & $\mathrm{AB}$ & 82.71 & $\mathrm{AB}$ & 81.40 & B \\
\hline 3 & 80.94 & $\mathrm{~A}$ & 80.39 & $\mathrm{BC}$ & 81.98 & $\mathrm{~A}$ & 80.81 & $\mathrm{~B}$ & 80.78 & B & 82.18 & $\mathrm{AB}$ & 81.18 & $\mathrm{BC}$ \\
\hline 4 & 80.90 & A & 82.93 & A & 81.72 & A & 82.70 & A & 82.68 & A & 83.46 & A & 82.40 & A \\
\hline 5 & 80.95 & A & 80.04 & $\mathrm{BC}$ & 81.99 & A & 81.03 & $\mathrm{~B}$ & 80.63 & B & 81.81 & $\mathrm{AB}$ & 81.08 & $\mathrm{BC}$ \\
\hline Mean & 80.91 & & 80.62 & & 81.93 & & 80.97 & & 81.21 & & 82.37 & & & \\
\hline
\end{tabular}

Means followed by the same letter vertically do not differ from each other by the Tukey test at $5 \%$ probability.

potential for the wet-processed fermented coffee with the use of yeasts. No significant functional relationships were observed between global score and altitude, at $5 \%$ probability.

Based on the data of Table 1, for the altitude of 907 meters, the five proposed treatments did not present statistical differences by the Tukey test at $5 \%$ of significance. In the second altitude range, at 969 meters, treatment 4-dry fermentation with yeasts (F.W.Y), showed statistical difference from the other treatments, at $5 \%$ of significance by the Tukey test. Thereafter, treatment 2 did not differ from treatment 3 and 5, but differed from treatment 1 and 4, at 5\% significance. Finally, treatment 1 showed the worst sensory results in terms of absolute numbers.

In the third experimental range, at 1005 meters altitude, the treatments did not present statistical differences among themselves at $5 \%$ of significance. In the 1021-meter range, treatment 4, dry fermentation with yeasts (F.W.Y) differed from the others at $5 \%$ significance and consequently had the best sensory results.

In the experimental range of 1052 meters of altitude, treatment 4 did not differ from treatment 2 , at $5 \%$ of significance, but it differed from the others. It is observable that both treatments that used yeasts had higher scores than the other methods used in the wet processing.

Finally, in the last experimental range, treatment 4 did not differ from treatments, 2, 3 and 5, but differed from treatment 1 , at $5 \%$ significance. Once again, treatment 4 presented the best sensory results relative to the overall scores.

In the overall mean of the experiments, treatment 4 differed from the other treatments, at $5 \%$ significance. Among treatments 2, 3 and 5 there are no statistical differences; however, treatment 2 differs from treatment 1 , at $5 \%$ significance.

It is possible to infer from the sensory results that all coffees submitted to spontaneous or induced fermentation appear in groups of Specialty coffees, as directed by the Specialty Coffee Association of America, SCAA, that is, they are above the cutoff of 80 points. We observed that treatment 4 (dry fermentation 
with yeast culture) stands out from the other treatments. It was possible to understand that in the sensory perception, the results found are in agreement with the results of [15] and the according with [2] [16] these differences in sensory attributes can probably be attributed to the fermentation process through wet processing.

However, the effects of fermentation during wet processing on the aroma profile of coffee are not completely elucidated and are often neglected, as the literature has argued that the main function of fermentation is the removal of mucilage [17]. The commercially available starter cultures for fermentation are not designed directly to ferment coffee beans, mainly due to the physical and chemical peculiarities of this process [18], reinforcing the need for further studies on the microbiota and the exact conditions of use.

In a complementary way, a multivariate analysis was performed using dendrograms to observe clustering in area (altitude/processing). Figure 1 shows the graphical distribution of the studied points. The dendrogram of Figure 1 suggests the existence of three homogeneous clusters: cluster A, formed by points (altitude/treatment) 9, 19,24, 27 and 29; cluster B, formed by point 6 and cluster C, formed by the other points.

Observing the data dispersion in Figure 1, cluster A grouped the best sensory results, being constituted by: point 9-altitude 2-fully washed with yeast method; followed by point 19-altitude 4 and FWY method; point 24-altitude 5 and FWY method; point 27, altitude 6 and yeast fermentation method; and point 29 , altitude 6 and FWY method.

The second cluster, composed of point 6 , isolated the method of spontaneous fermentation with water from all other process ses, at 969 meters, indicating that the use of starter cultures was favorable for the other study areas. The same qualitative relationship was observed for the spontaneous fermentation method in warmer and lower altitude zones. Lastly, all other points compose cluster C. Wecould only observe distancing in point 10 , relative to altitude 2 , method 5

\section{Euclidiane Distance Avarage}

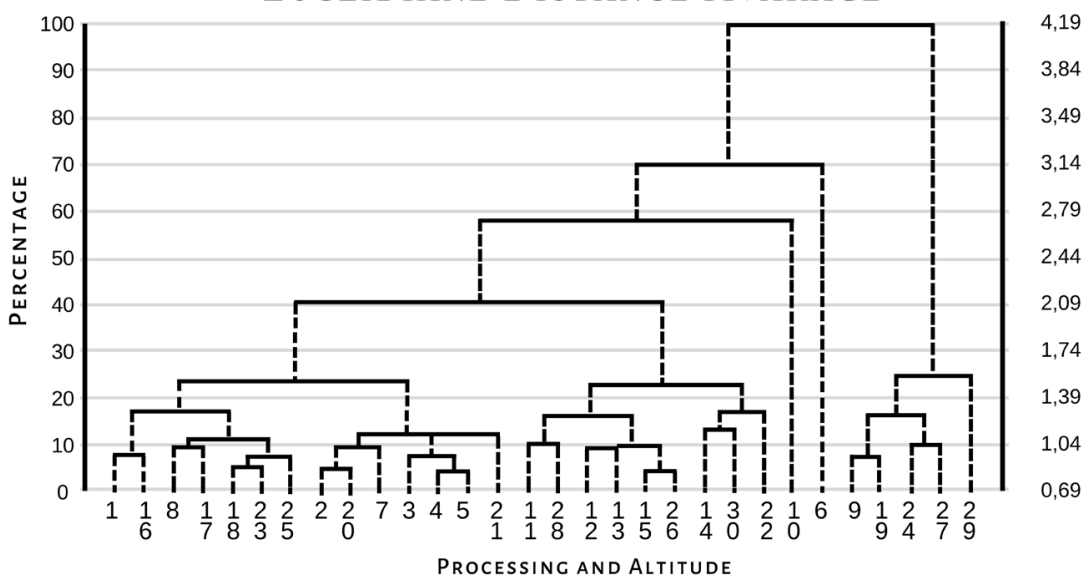

Figure 1. Distribution of clusters with 24 points, 6 altitudes and 5 processes. 
(semi-dry). In this experimental group, the worst results are clustered, therefore, it is necessary to relativize, that in this case, the observed low scores cannot reflect directly on the methods, but rather on the raw material of this area [5].

For the construction of the dendrograms, the variables that contributed the most to the clustering were fragrance $(23.4 \%)$, body (18.6\%), aftertaste (10.6\%), acidity (7.13\%), balance (5.76\%), flavor (3.68\%), and overall score (29.9\%). Based on this indication, it is possible to infer about the cupping tasters' choice profile, which draws attention to the strong contribution of the variables overall, fragrance and body as decisive factors of choice. The consumer preferences for a particular type of coffee, or even for the method of preparation, may be influenced by several factors, such as culture, lifestyle, social and work environment, daily habits and financial aspects, besides, of course, the flavor and hence, the importance of calibration and international certification. In the case of the cupping tasters used in this study, it was observed that most of the coffees that are evaluated in Casa Brasil Coffees in relation to preference belong to the group of naturals ${ }^{2}$, that is, sensorial profile that much resembles the fermented coffee using yeasts [19].

Thus, two relevant observations can be considered, the first on the possibility of modification of the metabolic routes and consequently change of sensory profile [18] [20]. The according to [21], one of the main problems in using experts in sensory evaluation is that the expert qualification (cupping tasters) is not well defined. In accordance with ISO 856-2 (1994), experience is not only the main criterion of a specialist, since it must be trained and have high sensory sensitivity.

The results demonstrated potential for wet-processed fermented coffee from the perspective of North American cupping tasters. In sequence, we suggest the comparison of the evaluated coffees by Brazilian cupping tasters, to measure the possible associations of preference according to the different types of prepared coffees.

\section{Conclusions}

Dry fermented coffee beans with cultures of Saccharomyces cerevisiae showed a higher sensory profile than all other methods. The advantage in using this technique is directly related to the reduction of water consumption by $89 \%$, in the post-harvest stage.

All groups of yeast-fermented coffees presented clustering homogeneity, regardless of the experimental range, indicating a potential of preference of this sensory profile for North American graders.

Future research should be carried out to measure the level of acceptance of Brazilian cupping tasters as well as internal and external consumers about the potential for acceptance of wet processed coffee under different methods.

${ }^{2}$ Naturals: postharvest processing method; at this stage, the fruits are only washed, where the floaters are separated and the other fruits are taken for drying. In Brazil, this method is commonly known as "via-seco". 


\section{Acknowledgements}

We thank the Federal Institute of Espírito Santo, Coffe Analysis and Research Laboratory-LAPC, Venda Nova do Imigrante Campus, Casa Brasil Coffees for the disposal of the laboratories and cupping tasters for the accomplishment of the experiments and studies and National Council for Scientific and Technological Development (CNPq)-number 469058/2014-5.

\section{Conflicts of Interest}

The authors declare no conflicts of interest regarding the publication of this paper.

\section{References}

[1] Companhia Nacional de Abastecimento (CONAB) (2018) Acompanhamento da safra brasileira de café: Primeiro levantamento. 5-SAFRA 2018, 1-73.

[2] Lee, L.W., Cheong, M.W., Curran, C., Yu, B. and Liu, Q.S. (2016) Modulation of Coffee Aroma via the Fermentation of Green Coffee Beans with Rhizopus oligosporus. I. Green coffee. Food Chemistry, 211, 916-924. https://doi.org/10.1016/j.foodchem.2016.05.076

[3] Pereira, L.L., Guarçoni, R.C, Souza, G.S., Junior Brioschi, D., Moreira, T.R. and Caten, C.S.T. (2018) Propositions on the Optimal Number of Q-Graders and RGraders. Journal of Food Quality, 2018, Article ID: 3285452. https://doi.org/10.1155/2018/3285452

[4] Lin, C.C. (2010) Approach of Improving Coffee Industry in Taiwan-Promote Quality of Coffee Bean by Fermentation. The Journal of International Management Studies, 5, 154-159.

[5] Pereira, L.L., Guarçoni, R.C., Ferrão, M.A., Fonseca, A.F.A. and Caten, C.S.T. (2017) Los caminos de la qualidade: Un estudio sobre la visión de expertos e produtores rurales a respeto e processos y tecnologias. International Journal of Knowledge Engineering and Management (IJKEM), 6, 73-89.

[6] Quintero, G.I.P. and Molina, J.G.E. (2015) Fermentación controlada del café: Tecnología para agregar valor a la calidad. Avances Técnicos. Cenicafé, 454, 1-12.

[7] Centro Nacional de Investigaciones de Café (2015) Avanços técnicos, Programa de Investigación Científica Fondo Nacional del Café. CENICAFÉ, Colômbia.

[8] Feria-Morales, A.M. (2002) Examining the Case of Green Coffee to Illustrate the Limitations of Grading Systems/Expert Tasters in Sensory Evaluation for Quality Control. Food Quality and Preference, 13, 355-367. https://doi.org/10.1016/S0950-3293(02)00028-9

[9] Di Donfrancesco, B., Gutierrez G.N. and Chambers, E. (2014) Comparison of Results from Cupping and Descriptive Sensory Analysis of Colombian Brewed Coffee. Journal of Sensory Studies, 29, 301-311. https://doi.org/10.1111/joss.12104

[10] Arce, A.R. and Linnemann, A.R. (2010) The Predictive Value of a Small Consumer Panel for Coffee-Cupper Judgment. British Food Journal, 112, 1023-1032. https://doi.org/10.1108/00070701011074372

[11] Pereira, L.L., Guarçoni, R.C., Pilini, I.C., Cardoso, W.S. and Caten, C.S.T. (2016) Tamanho Ótimo do Número de Provadores de Café com Uso do Protocolo SCAA-Great Size Number of Coffee Tasters With the Use of SCAA Protocol. Simposio Internacional De Ingenieria Industrial: Actualidad Y Nuevas Tendencias, 


\section{9, 20-21.}

[12] Specialty Coffee Association of American (2015) Protocols. SCAA, Santa Ana, CA. http://www.scaa.org/PDF/resources/cupping-protocols.pdf

[13] Pereira, L.L., Guarçoni, R.C., Cardoso, W.S., Taques, R.C., Moreira, T.R., Silva, S.F. and Caten, C.S.T. (2018) Influence of Solar Radiation and Wet Processing on the Final Quality of Arabica Coffee. Journal of Food Quality, 2018, Article ID: 6408571. https://doi.org/10.1155/2018/6408571

[14] Hair, J.F., Black, W.C., Babin, B.J., Anderso, R.E. and Tatham, R.L. (2009) Análise multivariada de dados. 6th Edition, Bookman, Porto Alegre.

[15] Evangelista, S.R., Miguel, M.G.P.C., Cordeiro, C.S., Silva, C.F., Pinheiro, A.C.M. and Schwan, R.F. (2014) Inoculation of Starter Cultures in a Semi-Dry Coffee (Coffea arabica) Fermentation Process. Food Microbiology, 44, 87-95. https://doi.org/10.1016/j.fm.2014.05.013

[16] Lee, L.W., Taya G.Y., Cheong, M.W., Curran P., Yu B. and Liu S.Q. (2017) Modulation of the Volatile and Non-Volatile Profiles of Coffee Fermented with Yarrowia lipolytica: I. Green Coffee. LWT-Food Science and Technology, 77, 225-232. https://doi.org/10.1016/j.lwt.2016.11.047

[17] Lee, L.W., Cheong, M.W., Curran, P., Yu, B. and Liu, S.Q. (2015) Coffee Fermentation and Flavor-An Intricate and Delicate Relationship. Food Chemistry, 185, 182-191. https://doi.org/10.1016/j.foodchem.2015.03.124

[18] De Mello, P.G.V., Neto, E., Soccol, V.T., Medeiros, A.B.P., Woiciechowski, A.L. and Soccol, C.R. (2015) Conducting Starter Culture-Controlled Fermentations of Coffee Beans during On-Farm Wet Processing: Growth, Metabolic Analyses and Sensorial Effects. Food Research International, 75, 348-356. https://doi.org/10.1016/j.foodres.2015.06.027

[19] Gloess, A.N., Schönbächler, B., Ambrosio, L. Chatelain, K., Bongartz, A., Strittmatter, A., Rast, M. and Yeretzian, C. (2013) Comparison of Nine Common Coffee Extraction Methods: Instrumental and Sensory Analysis. European Food Research and Technology, 236, 607-627. https://doi.org/10.1007/s00217-013-1917-x

[20] Evangelista, S.R., Silva, C.F., Miguel, M.G.P.C., Cordeiro, C.S., Pinheiro, A.C.M., Duarte, W.F. and Schwan, R.F. (2014) Improvement of Coffee Beverage Quality by Using Selected Yeasts Strains during the Fermentation in Dry Process. Food Research International, 61, 183-195. https://doi.org/10.1016/j.foodres.2013.11.033

[21] Dzung, N.H., Dzuan, L. and Tu, H.D. (2003) The Role of Sensory Evaluation in Food Quality Control, Food Research and Development: A Case of Coffee Study. Proceeding of the 8th Asean Food Conference, Hanoi, 8-11 October 2003, 862-866. 